PAULUS D; VALMORBIDA R; FERREIRA SB; ZORZZI IC; NAVA GA. 2016. Biomassa e composição do óleo essencial de manjericão cultivado sob malhas fotoconversoras e colhido em diferentes épocas. Horticultura Brasileira 34: 046-053. DOI - http://dx.doi.org/10.1590/S0102-053620160000100007

\title{
Biomassa e composição do óleo essencial de manjericão cultivado sob malhas fotoconversoras e colhido em diferentes épocas
}

\author{
Dalva Paulus; Raquel Valmorbida; Sintieli B Ferreira; Ivan C Zorzzi; Gilmar A Nava \\ Universidade Tecnológica Federal do Paraná (UTFPR), Dois Vizinhos-PR, Brasil; dalvaufsmdeutch@yahoo.com.br (autor para \\ correspondência); raquelvalmorbida@yahoo.com.br; sinti_eli@hotmail.com; ivanzorzzi@hotmail.com; gilmarnava@utfpr.edu.br
}

\section{RESUMO}

Objetivou-se avaliar o efeito das malhas fotoconversoras e épocas de colheita no crescimento, produção de biomassa, teor e composição química do óleo essencial de manjericão (Ocimum basilicum var. citriodorum). $\mathrm{O}$ experimento foi conduzido na área experimental da Universidade Tecnológica Federal do Paraná, Campus Dois Vizinhos. Foram estudadas quatro épocas de avaliação (90, 120, 150 e 180 dias após o transplantio) e três malhas fotoconversoras (malha aluminizada, malha vermelha, malha preta e pleno sol), todas com $50 \%$ de irradiância. Os tratamentos foram arranjados em esquema fatorial $4 \times 4$, com parcelas subdivididas, no delineamento experimental blocos ao acaso, com três repetições. O cultivo sob malha aluminizada favoreceu o crescimento em altura e diâmetro. Plantas cultivadas a pleno sol resultaram em maior biomassa fresca e seca e maior teor e rendimento de óleo essencial em relação às malhas fotoconversoras. A colheita do manjericão realizada aos 120 dias após o transplantio resultou em maior produção de óleo essencial $(0,77 \mathrm{~g} /$ planta) e teor de citral (78,26\%). O componente majoritário do óleo essencial foi o citral, obtido nas plantas cultivadas sob malha preta $(73,25 \%)$, aluminizada $(72,14 \%)$ e pleno sol $(71,86 \%)$, respectivamente.

Palavras-chave: Ocimum basilicum, manjericão, citral, radiação, sazonalidade.

\begin{abstract}
Biomass production and essential oil composition of basil grown under shading nets and harvested at different times

This study aimed to evaluate the effect of harvest seasons and shading nets in the growth, production, content and chemical composition of essential oil of basil. The experiment was carried out in the experimental area of the Universidade Tecnológica Federal do Paraná, Campus Dois Vizinhos, Brazil. Four harvest dates (90, 120, 150 and 180 days after transplanting) and three shading nets (aluminized net, red net, black net and full sun), all with $50 \%$ irradiance were evaluated. The treatments were arranged in a split-plot $4 \times 4$ factorial design with three replications in randomized blocks. Cultivation under aluminized net favored the growth in height and diameter. Basil plants grown under full sun resulted in higher fresh and dry biomass and higher content of essential oil yield in relation to shading nets. The best harvesting period was at 120 days after transplanting and resulted in higher production of essential oil ( 0.77 g/planta) and citral content (78.26\%). The major component of the essential oil was the citral obtained in plants grown under black net (73.25\%), aluminized (72.14\%) and full sun (71.86\%).
\end{abstract}

Keywords: Ocimum basilicum, citral, radiation, seasonality.

(Recebido para publicação em 28 de maio de 2014; aceito em 18 de junho de 2015) (Received on May 28, 2014; accepted on June 18, 2015)

$\mathrm{O}$ manjericão (Ocimum basilicum var. citriodorum) é uma planta aromática e medicinal, nativo da Ásia e introduzido no Brasil pela colônia italiana. Conhecido popularmente como manjericão-italiano, manjericão roxo ou alfavaca, apresenta grande importância econômica, pois é fonte de óleo essencial, usado no preparo de perfumes, cosméticos, condimentos, repelentes de insetos e na indústria farmacêutica (Khosla \& Sobti, 1985). É recomendado para problemas digestivos em geral na forma de infusão, indicado contra problemas nas vias respiratórias, infecções bacterianas e parasitas intestinais, além de melhorar a digestão dos alimentos
(Lorenzi \& Matos, 2008).

Segundo Vieira et al. (2003), a cultivar de manjericão Limoncino (Ocimum basilicum var. citriodorum) é um híbrido entre manjericão verdadeiro (Ocimum basilicum) e manjericão branco (Ocimum americanum); apresenta forte aroma de limão, conferido pelo citral, constituinte majoritário de seu óleo essencial (Tansi \& Nacar, 2000). O óleo essencial tem sido muito usado como condimento em carnes, saladas, bebidas não alcoólicas, sorvetes e na indústria de perfume e produtos de higiene bucal (Loughrin \& Kasperbauer, 2001).

As constantes alterações climáticas e as exigências do mercado por produ- tos de qualidade têm contribuído para que produtores de hortaliças busquem tecnologias de produção que permitem produzir em condições ambientais adversas (altas temperaturas, radiação solar, ventos). No cultivo protegido, uma das alternativas é a utilização de filtros espectrais, que transmitem seletivamente certos comprimentos de ondas (Costa et al., 2012), os quais resultam em alterações nas funções fisiológicas, na morfologia, no crescimento e desenvolvimento das plantas, como resposta à adaptação a uma condição ambiental diferenciada de luminosidade (Tsormpatsidis et al., 2008).

As malhas fotoconversoras Chro- 
matinet alteram o espectro de luz transmitido, dentre elas, a malha vermelha, que apresenta maior transmitância em comprimentos de onda acima de $590 \mathrm{~nm}$ (vermelho) e um pico menor em torno de $400 \mathrm{~nm}$ (violeta), reduzindo ondas azuis, verdes e amarelas. Sendo assim, a luz vermelha atua no desenvolvimento da estrutura fotossintética, favorecendo o crescimento das plantas (Shahak et al., 2004).

A malha termorefletora aluminizada, conhecida comercialmente por Aluminet ${ }^{\circledR}$, permite manejar a diferença de temperatura entre o dia e a noite, protegendo as espécies vegetais da radiação solar excessiva e conservando o calor no interior do ambiente no período do inverno. É utilizada no cultivo de espécies ornamentais, hortícolas e frutíferas, proporcionando resultados significativos na produção de biomassa (Leite et al., 2008). A malha preta (sombrite) é considerada neutra, sem influência na qualidade espectral da luz, atua apenas na redução da incidência de radiação sobre as plantas (Oren-Shamir et al., 2001).

A biossíntese dos óleos essenciais é influenciada por fatores climáticos como fotoperíodo, temperatura, umidade, precipitação e intensidade de radiação solar, que podem determinar a época ideal de colheita, para se obter maior quantidade de óleo essencial e do princípio ativo desejado. O estádio de desenvolvimento da planta também interfere na produção de metabólitos secundários (Taveira et al., 2003). Tansi \& Nacar (2000), em trabalhos realizados com Ocimum basilicum var. citriodorum observaram que o constituinte principal do óleo essencial foi o citral $(89,28 \%)$ e foi na época da floração que a planta produziu mais óleo $(0,71 \%)$.

Dentre os relatos da literatura sobre a influência das malhas coloridas no crescimento, produção e teor de óleo essencial de espécies de manjericão, cita-se o de Martins et al. (2008), que em cultivo de $O$. gratissimum sob malhas coloridas azul, preta e vermelha, verificaram que o teor de óleo essencial das plantas cultivadas sob malha azul foi de $1,19 \%$, o que correspondeu a um acréscimo de $142 \%$ em relação ao teor verificado nas plantas cultivadas a pleno sol. Os autores constataram que o sombreamento de $50 \%$ favorece a produção de óleo essencial em $O$. gratissimum e que a luz pode ser modulada durante o cultivo a fim de se obter características morfológicas desejáveis e maximizar a produção de princípios ativos nessa espécie.

O objetivo do trabalho foi avaliar o efeito das malhas fotoconversoras e épocas de colheita no crescimento, produção, teor e composição química do óleo essencial de manjericão.

\section{MATERIAL E MÉTODOS}

O experimento foi conduzido na área experimental do Setor de Olericultura da Universidade Tecnológica Federal do Paraná, Campus Dois Vizinhos, na região ecoclimática do Sudoeste do Paraná (25024'2'S, 53020'6"O, altitude média $520 \mathrm{~m}$ ) (INMET, 2012). O solo local é do tipo Nitossolo Vermelho Distroférrico (Bhering et al., 2008), que apresentou em pré-plantio sob as malhas de cultivo e a pleno sol, as seguintes características químicas, na camada de 0 a 20 cm de profundidade: $\mathrm{pH}=6,6$; matéria orgânica $\left(\mathrm{g} / \mathrm{dm}^{3}\right)=54,95 ; \mathrm{P}, \mathrm{Cu}, \mathrm{Fe}, \mathrm{Zn}$, $\mathrm{Mn}\left(\mathrm{mg} / \mathrm{dm}^{3}\right)=1.422,35 ; 5,71 ; 47,53 \mathrm{e}$ 198,54, respectivamente; $\mathrm{K}, \mathrm{Ca}, \mathrm{Mg}$, $\mathrm{SB}, \mathrm{H}+\mathrm{AI}\left(\mathrm{cmolc} / \mathrm{dm}^{3}\right)=1,95 ; 11,81$; 4,57; 18,33 e 2,70, respectivamente; $\mathrm{V}$ $(\%)=87,16$ e $\mathrm{CTC}=21,03$; e em campo: $\mathrm{pH}=6,7$; matéria orgânica $\left(\mathrm{g} / \mathrm{dm}^{3}\right)=$ 53,61; $\mathrm{P}, \mathrm{Cu}, \mathrm{Fe}, \mathrm{Zn}, \mathrm{Mn}\left(\mathrm{mg} / \mathrm{dm}^{3}\right)=$ $1.355,78 ; 2,51 ; 24,91 ; 27,37$ e 202,21, respectivamente; $\mathrm{K}, \mathrm{Ca}, \mathrm{Mg}, \mathrm{SB}, \mathrm{H}+\mathrm{AI}$ $\left(\right.$ cmolc dm$\left.^{-3}\right)=1,95 ; 11,81 ; 4,57 ; 18,33$ e 2,70 respectivamente; $\mathrm{V}(\%)=87,16$ e CTC $=19,23$.

Foram estudadas quatro épocas de colheita, que corresponderam a 90, 120,150 e 180 dias após o transplantio (DAT) e três malhas fotoconversoras: malha aluminizada (Aluminet), malha vermelha (Chromatinet), malha preta (Sombrite) e pleno sol (testemunha). Os tratamentos foram arranjados em esquema fatorial $4 \times 4$, com parcelas subdivididas, no delineamento experimental blocos ao acaso, com três repetições. Todas as malhas avaliadas interceptaram a radiação solar em 50\%. As malhas foram instaladas sob ambiente protegi- do a 2,0 m de altura do solo. A área de cada parcela (épocas de colheita) foi de $12 \mathrm{~m}^{2}(2 \times 6 \mathrm{~m})$, enquanto da subparcela (malhas de sombreamento), de $3 \mathrm{~m}^{2}$ $(1,5 \times 2,0 \mathrm{~m})$.

A cultivar avaliada foi $O$. basilicum var. citriodorum que foi reproduzida por meio de sementes em bandejas de poliestireno expandido, com 128 células, contendo substrato comercial Mecplant $^{\circledR}$, sob nebulização intermitente. As plantas com $7 \mathrm{~cm}$ de altura e seis folhas definitivas foram transplantadas nos canteiros com dimensões de 2,0x1,5 $\mathrm{m}$, no espaçamento de $0,5 \times 0,4 \mathrm{~m}$ entre linhas e entre plantas, respectivamente. A adubação de plantio foi de $2 \mathrm{~kg} / \mathrm{m}^{2}$ de cama de aviário compostada (Blank et al., 2010). Durante o período de cultivo foram realizadas irrigações por gotejamento conforme a necessidade da cultura. $\mathrm{O}$ controle de plantas espontâneas foi por meio de capinas manuais.

Os dados meteorológicos (temperatura e umidade relativa do ar) foram obtidos de datalogers instalados sob cada malha. Os valores médios de temperatura e umidade, respectivamente, foram: malha aluminizada: $19,00^{\circ} \mathrm{C}$; $86,25 \%$; malha preta: $20,05^{\circ} \mathrm{C} ; 83,54 \%$; malha vermelha: $20,29^{\circ} \mathrm{C} ; 81,96 \%$; pleno sol: $19,56^{\circ} \mathrm{C} ; 79,43 \%$. Os valores de radiação e precipitação, respectivamente: fevereiro: $793,73 \mathrm{kJm}^{2}$ e $239,4 \mathrm{~mm}$; março: 756,39 kJm² e 358,2 mm; abril: 701,67 kJm² e 89,8 mm; maio: 700,35 $\mathrm{kJm}^{2}$ e 286,4 mm; junho: 964,25 kJm² e $538,8 \mathrm{~mm}$, foram obtidos da estação meteorológica (16 UTC) da UTFPR, Campus Dois Vizinhos, localizada próxima à unidade experimental.

Foram analisadas a altura das plantas (com trena métrica, desde o colo até o ápice da planta), diâmetro (à altura do colo com paquímetro digital, determinadas quinzenalmente, dos 15 aos 75 DAT). Verificou-se que após os 75 DAT, estabilizou o crescimento em altura e diâmetro, não justificando continuar com as avaliações dessas características.

A área foliar foi obtida pelo método dos discos foliares em quatro épocas (90, 120, 150 e 180 DAT), de acordo com metodologia descrita por Fernandes (2000). Foram coletadas folhas apicais, basais e medianas, das quais retiraram-se 50 discos com área de 0,636 $\mathrm{cm}^{2}$ 
de cada folha. As clorofilas a, b e total foram determinadas nas folhas da parte apical, basal e mediana de três plantas por parcela, com clorofilômetro clorofilog $\left(\right.$ Falker $\left.^{\circledR}\right)$ nas mesmas épocas da área foliar.

As biomassas fresca e seca da parte aérea foram determinadas aos 90, 120, 150 e 180 DAT. As plantas foram coletadas às 8:00 horas, pesadas em balança de precisão e secas em estufa de circulação de ar forçada a uma temperatura de $40^{\circ} \mathrm{C}$ até massa constante.

O teor de óleo essencial foi obtido da coleta de plantas de manjericão de todos os tratamentos por meio de extração dos componentes voláteis realizado em aparelho modificado do tipo Clevenger (método de hidrodestilação) por 1:20 h. As amostras para extração eram de 70 $\mathrm{g}$ de folhas e inflorescências secas em estufa de circulação de ar forçada a uma temperatura de $40^{\circ} \mathrm{C}$ até massa constante. Após a obtenção do óleo essencial foram obtidos massa e o teor, calculados pela fórmula $\mathrm{T} \%=$ massa do óleo $(\mathrm{g}) /$ 70 g x 100 e a produção de óleo (PO) em litros por hectare considerando a densidade do óleo essencial como sendo de $0,9 \mathrm{~g} / \mathrm{cm}^{3}$.

As análises químicas do óleo essencial foram realizadas em sistema de cromatografia gasosa de alta resolução, em cromatógrafo a gás HP 7820-(Agilent), coluna: HP5 $30 \mathrm{~m}$ x 0,32 mm x 0,25 $\mu \mathrm{m}$ (Agilent); temp. da coluna: $70^{\circ} \mathrm{C}(0 \mathrm{~min}), 3^{\circ} \mathrm{C} / \mathrm{min}$, até $200^{\circ} \mathrm{C}$. Injetor: $220^{\circ} \mathrm{C}$ Split: $1 / 50$. Detector FID: $220^{\circ} \mathrm{C}$. Gás de arraste: $\mathrm{H}_{2}$ a $2 \mathrm{~mL} / \mathrm{min}$. Vol. de injeção: $1 \mu \mathrm{L}$. Concentração da amostra: 1,0\% em clo- rofórmio. Software de aquisição de dados: EZChrom Elite Compact (Agilent).

Os resultados das características analisadas foram submetidos à análise de variância com teste $F(p<0,01)$ e aos tratamentos quantitativos (quatro épocas de colheita) foram ajustados modelos de regressão, sendo selecionadas dentro da equação de regressão, aquelas de efeito significativo pelo teste F, a $1 \%$ de probabilidade, com auxílio do programa "SAS" (SAS, 1999). As variâncias dos tratamentos foram testadas quanto à homogeneidade pelo teste de Bartlett e as médias comparadas pelo teste de Tukey a 5\% de probabilidade.

\section{RESULTADOS E DISCUSSÃO}

Não houve interação significativa entre malhas fotoconversoras e épocas de colheita para nenhuma das características analisadas de manjericão. Verificou-se que as plantas de manjericão apresentaram alterações no crescimento em função das diferentes cores das malhas de sombreamento. Plantas crescidas sob malha aluminizada apresentaram maior crescimento em altura $(66,58 \mathrm{~cm})$ e a pleno sol, a menor altura $(53,01 \mathrm{~cm})$ (Tabela 1). Os resultados de altura corroboram com os de Biasi \& Dechamps (2009), pois segundo os autores, o crescimento do manjericão é ereto, atingindo altura variável entre 0,6 a 1,0 m. De acordo com Fiallo et al. (1996), o manjericão pode ser considerado uma espécie heliófita, sendo o alongamento do caule uma resposta para evitar a sombra, para assim ter maior

Tabela 1. Altura, diâmetro do colo (DC), área foliar e clorofila a, b e total de manjericão cultivado sob malhas fotoconversoras (height, stem diameter (DC), leaf area and chlorophyll $\mathrm{a}, \mathrm{b}$ and total of basil grown under shading nets). Dois Vizinhos, UTFPR, 2013.

\begin{tabular}{|c|c|c|c|c|c|c|}
\hline \multirow{2}{*}{ Malhas } & Altura & $\overline{D C}$ & \multirow{2}{*}{$\begin{array}{l}\text { Área foliar } \\
\left(\mathrm{cm}^{2} / \text { planta }\right)\end{array}$} & \multicolumn{3}{|c|}{ Clorofila (unidade SPAD) } \\
\hline & \multicolumn{2}{|c|}{ (cm) } & & a & b & Total \\
\hline Aluminizada & $66,58 a^{*}$ & $1,10 \mathrm{a}$ & $1840,22 \mathrm{a}$ & $43,58 \mathrm{a}$ & $7,66 \mathrm{a}$ & $50,58 \mathrm{a}$ \\
\hline Preta & $57,28 \mathrm{~b}$ & $0,98 \mathrm{~b}$ & $1617,75 b$ & $43,30 \mathrm{a}$ & $7,36 \mathrm{a}$ & $50,46 \mathrm{a}$ \\
\hline Vermelha & $59,61 \mathrm{~b}$ & $0,94 \mathrm{~b}$ & $1600,58 \mathrm{~b}$ & $42,31 \mathrm{a}$ & $7,38 \mathrm{a}$ & $49,69 \mathrm{a}$ \\
\hline Pleno sol & $53,01 \mathrm{c}$ & $0,90 \mathrm{~b}$ & $1674,93 \mathrm{~b}$ & $44,40 \mathrm{a}$ & $7,69 \mathrm{a}$ & $51,93 \mathrm{a}$ \\
\hline CV (\%) & 11 & 19 & 10 & 5 & 10 & 6 \\
\hline
\end{tabular}

*Médias seguidas de mesma letra nas colunas não diferem significativamente entre si pelo teste de Tukey, $\mathrm{p}<0,05$ (means followed by the same letter in the column do not differ by Tukey test, $\mathrm{p}<0.05)$. captação de energia luminosa.

O maior diâmetro do colo $(1,06 \mathrm{~cm})$ foi observado sob malha aluminizada (Tabela 1), evidenciando que a redução da intensidade de luz, sem a alteração da qualidade espectral, proporciona plantas de caule mais delgado (Martins et al., 2008).

O cultivo de manjericão sob malha aluminizada proporcionou maior área foliar $\left(1840,22 \mathrm{~cm}^{2}\right)$ que o cultivo sob malha preta, vermelha e pleno sol (Tabela 1). Os menores valores de área foliar verificados nas plantas crescidas sob malha vermelha, preta e sob pleno sol indicam que ocorreu menor alocação de fotoassimilados para as folhas. Em estudos com $O$. gratissimum sob malhas coloridas azul, preta e vermelha, Martins et al. (2008) verificaram maiores áreas foliares sob as malhas azul e vermelha que o cultivo a pleno sol.

Não houve diferença significativa entre as malhas fotoconversoras para clorofila a, clorofila b e total evidenciando que essas características não sofreram influência quanto às cores das malhas (Tabela 1). Souza et al. (2011) observaram em guaco (Mikania laevigata) que plantas mantidas a pleno sol tiveram os menores teores de clorofila a e b comparado às malhas vermelha, cinza e azul.

Constatou-se que a altura apresentou um ajuste linear, chegando aos 75 DAT com 92,46 cm (Figura 1a). Albuquerque \& Honório (2008), estudando a mesma espécie, observaram que aos 70 DAT as plantas estavam com $63,8 \mathrm{~cm}$ de altura.

Para o diâmetro do colo houve um ajuste polinomial, com valores crescentes até os 75 DAT (Figura 1b), o que permite afirmar que a planta estaria direcionando sua energia para outras funções, além do crescimento vegetativo, o período reprodutivo, uma vez que, aos 75 DAT as plantas estavam no estádio inicial de florescimento.

Analisando os dados de área foliar nas épocas avaliadas, verificou-se ajuste quadrático (Figura 1c). Observou-se que a maior área foliar $\left(2012,67 \mathrm{~cm}^{2}\right)$ ocorreu aos 150 DAT, possivelmente devido a um aumento no número de folhas por planta, ao invés de expansão foliar individual (Sifola \& Barbieri, 2006). Aos 180 DAT as plantas apresen- 


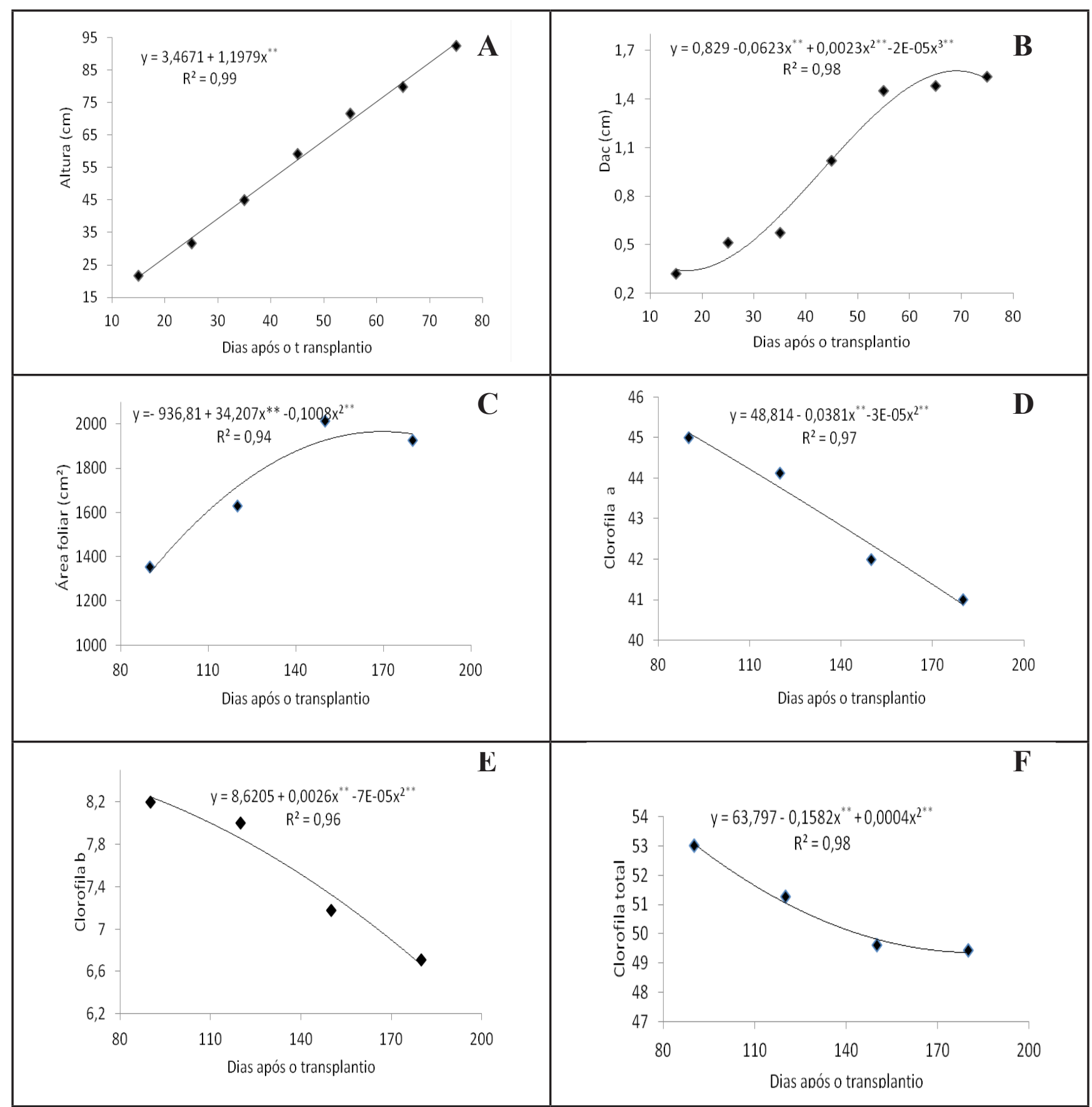

Figura 1. Altura (a); diâmetro do colo (Dc) (b); área foliar (c); clorofila a (d); clorofila b (e) e clorofila total (f) de manjericão em diferentes dias após o transplantio (DAT) \{height (a), stem diameter (Dc) (b), leaf area (c), chlorophyll a (d), chlorophyll b (e) and total chlorophyll (f) of basil at different days after transplanting (DAT); ** significativo a $1 \%$ de probabilidade pelo teste $\mathrm{F}(* *$ significant at $1 \%$ probability through the F test)\}. Dois Vizinhos, UTFPR, 2013.

taram abscisão das folhas e formação de sementes maduras.

Os valores de clorofila a, b e total apresentaram um ajuste quadrático ao longo do período (Figura 1d; 1e; 1f), com maiores valores de clorofila a (45); clorofila b $(8,20)$ e total $(53)$ aos 90 DAT, e decréscimo aos 180 DAT, possivelmente devido ao término do ciclo reprodutivo.
A biomassa fresca e seca aérea, teor, rendimento e produtividade de óleo essencial das plantas cultivadas a pleno sol foi maior que as dos demais ambientes de cultivo (Tabela 2). De acordo com Larcher (2004), as plantas heliófitas utilizam com eficiência altas intensidades de radiação graças à elevada capacidade do sistema de transporte de elétrons e, desta forma, conseguem maiores ganhos fotossintéticos, resultando em maior conteúdo energético de massa seca. As plantas crescidas sob malha preta foram as que acumularam a menor quantidade de biomassa fresca e seca aérea (Tabela 2).

$\mathrm{Na}$ literatura há relatos do aumento do teor de óleo essencial em plantas aromáticas com o aumento da taxa de luminosidade (Costa et al., 2010). A in- 
Tabela 2. Biomassa fresca (BFA) e seca da parte aérea (BSA), teor de óleo essencial (TOE), rendimento de óleo essencial (ROE) e produtividade de óleo essencial (POE) de manjericão cultivado sob malhas fotoconversoras (fresh biomass (BFA) and dry mass of the aboveground part (BSA), content of essential oil (TOE), essential oil yield (ROE) and yield of essential oil (POE) of basil grown under shading nets\}. Dois Vizinhos, UTFPR, 2013.

\begin{tabular}{|c|c|c|c|c|c|}
\hline \multirow{2}{*}{ Malhas } & BFA & BSA & \multirow{2}{*}{$\begin{array}{c}\text { TOE } \\
(\%)\end{array}$} & \multirow{2}{*}{$\begin{array}{c}\text { ROE } \\
\text { (g/planta) }\end{array}$} & \multirow{2}{*}{$\begin{array}{c}\text { POE } \\
\text { (L/ha) }\end{array}$} \\
\hline & \multicolumn{2}{|c|}{ (g/planta) } & & & \\
\hline Aluminizada & $596,83 b^{*}$ & $169,16 \mathrm{~b}$ & $0,86 \mathrm{~b}$ & $0,61 \mathrm{~b}$ & $27,58 \mathrm{~b}$ \\
\hline Preta & $473,87 \mathrm{c}$ & $144,42 \mathrm{~b}$ & $0,89 \mathrm{~b}$ & $0,59 \mathrm{~b}$ & $26,68 \mathrm{~b}$ \\
\hline Vermelha & $526,76 \mathrm{~b}$ & $165,71 \mathrm{~b}$ & $0,64 \mathrm{c}$ & $0,49 \mathrm{c}$ & $22,38 \mathrm{c}$ \\
\hline Pleno sol & $723,33 \mathrm{a}$ & $232,83 \mathrm{a}$ & $0,96 \mathrm{a}$ & $0,78 \mathrm{a}$ & $34,83 \mathrm{a}$ \\
\hline CV (\%) & 10 & 19 & 17 & 16 & 15 \\
\hline
\end{tabular}

*Médias seguidas de mesma letra nas colunas não diferem significativamente entre si pelo teste de Tukey, $\mathrm{p}<0,05$ (means followed by the same letter in the column do not differ significantly by Tukey test, $\mathrm{p}<0.05$ ).

tensidade solar é um fator que influencia a concentração, bem como a composição dos óleos essenciais. De acordo com Morais (2009), o desenvolvimento dos tricomas glandulares, estruturas vegetais que biossintetizam e armazenam o óleo essencial de $O$. basilicum são processos dependentes da luz.

$\mathrm{Na}$ malha vermelha foram constatados os menores valores de teor, rendimento e produtividade de óleo essencial (Tabela 2). Pode-se inferir que plantas de manjericão não respondem positivamente à utilização da malha vermelha para produção de óleo. Isso pode ter ocorrido devido à alteração no espectro de luz que incidiu nas plantas, pois a malha vermelha reduz as ondas azuis, verdes e amarelas e acrescentam ondas na faixa do vermelho a vermelho-distante, o que pode ter provocado a anulação de alguma rota importante para a síntese de terpenos, interferindo na produção de óleo essencial. Em estudos com melissa (Melissa officinalis) Brant et al. (2009) também encontraram menor rendimento $(0,06 \mathrm{~g} /$ planta $)$ e teor de óleo essencial $(0,34 \%)$ em malha vermelha.

Esses resultados evidenciam as respostas fisiológicas das plantas de manjericão às condições diferenciadas de espectros de luz fornecidas pelo uso das malhas coloridas. Assim, espécies do mesmo gênero podem apresentar respostas diferentes, uma vez que, em plantas de $O$. selloi, o sombreamento de $50 \%$ não causou variações na produção de óleo essencial em relação a pleno sol (Gonçalves et al., 2003). Também, Martins et al. (2008) constataram que plantas de $O$. gratissimum crescidas a pleno sol resultaram em menor teor de óleo essencial que em malhas coloridas (azul, vermelha e preta).

Os resultados de biomassa fresca da parte aérea, teor, rendimento e produtividade de óleo essencial apresentaram diferenças significativas em função das épocas de colheita avaliadas, apresentando efeitos quadráticos (Figuras 2a; $2 \mathrm{c}, 2 \mathrm{~d}$ e $2 \mathrm{e}$ ). A colheita realizada aos 120 dias após o transplantio resultou em maior biomassa fresca da parte aérea, teor, rendimento e produtividade de óleo essencial. Para biomassa seca da parte aérea não ocorreu efeito significativo em função das épocas avaliadas, sendo o valor médio de 173,03 g/planta. Constatou-se que nessa época de colheita as plantas estavam em plena floração, o que pode ter favorecido a síntese do óleo essencial. Também as condições climáticas favoráveis com temperatura média de $21,36^{\circ} \mathrm{C}$ e umidade relativa do ar de $82,4 \%$ favoreceram a produção de óleo essencial, evitando que óleo

Tabela 3. Componentes do óleo essencial (\%) de manjericão cultivado sob malhas fotoconversoras \{components of the essential oil (\%) of basil grown under shading nets \}. Dois Vizinhos, UTFPR, 2013.

\begin{tabular}{|c|c|c|c|c|c|c|}
\hline \multirow{2}{*}{ Componentes } & \multirow{2}{*}{ I.K.* } & \multicolumn{3}{|c|}{ Malhas fotoconversoras } & \multirow{2}{*}{ Pleno sol } & \multirow{2}{*}{ CV (\%) } \\
\hline & & Aluminizada & Preta & Vermelha & & \\
\hline Mirceno & 1048,21 & $0,44 b^{* *}$ & $0,43 b$ & $0,50 \mathrm{a}$ & $0,52 \mathrm{a}$ & 10 \\
\hline 1,8 Cineol & 1070,66 & $0,48 \mathrm{c}$ & $0,47 \mathrm{c}$ & $0,66 b$ & $0,82 \mathrm{a}$ & 12 \\
\hline Linalol & 1112,49 & $9,70 b$ & $9,06 b$ & $11,02 \mathrm{a}$ & $10,04 \mathrm{a}$ & 7 \\
\hline Citronelal & 1149,59 & $0,29 \mathrm{a}$ & $0,53 \mathrm{a}$ & $0,54 \mathrm{a}$ & $0,56 \mathrm{a}$ & 15 \\
\hline Terpinen-4ol & 1177,85 & $0,50 \mathrm{a}$ & $0,49 \mathrm{a}$ & $0,23 b$ & $0,52 \mathrm{a}$ & 18 \\
\hline Neral & 1231,93 & $30,86 a$ & $31,57 \mathrm{a}$ & $28,13 b$ & $30,42 \mathrm{a}$ & 11 \\
\hline Geranial & 1261,84 & $41,28 \mathrm{a}$ & $41,68 \mathrm{a}$ & $36,76 \mathrm{~b}$ & $41,44 a$ & 13 \\
\hline Eugenol & 1358,51 & $0,74 b$ & $0,71 \mathrm{~b}$ & $1,00 \mathrm{a}$ & $0,76 \mathrm{~b}$ & 8 \\
\hline$\beta$-Cariofileno & 1408,22 & $2,24 \mathrm{a}$ & $2,05 b$ & $1,75 \mathrm{c}$ & $2,20 \mathrm{a}$ & 11 \\
\hline Muuroleno & 1473,70 & $0,55 \mathrm{~d}$ & $0,84 \mathrm{~b}$ & $0,46 \mathrm{c}$ & $0,97 \mathrm{a}$ & 14 \\
\hline Butirato de geranila & 1544,35 & $2,42 b$ & $2,33 b$ & $2,17 \mathrm{c}$ & $2,55 \mathrm{a}$ & 9 \\
\hline Óxido de cariofileno & 1578,22 & $1,49 \mathrm{c}$ & $1,54 \mathrm{~b}$ & $3,07 \mathrm{a}$ & $1,52 \mathrm{~b}$ & 6 \\
\hline
\end{tabular}

*I.K. = índice de Kovats; **Médias seguidas das mesmas letras minúsculas nas linhas, em cada variável, não diferem estatisticamente pelo teste de Tukey, $\mathrm{p}<0,05$ (means followed by same lowercase letters in the lines in each variable are not statistically different by Tukey test, $\mathrm{p}<0,05)$. 


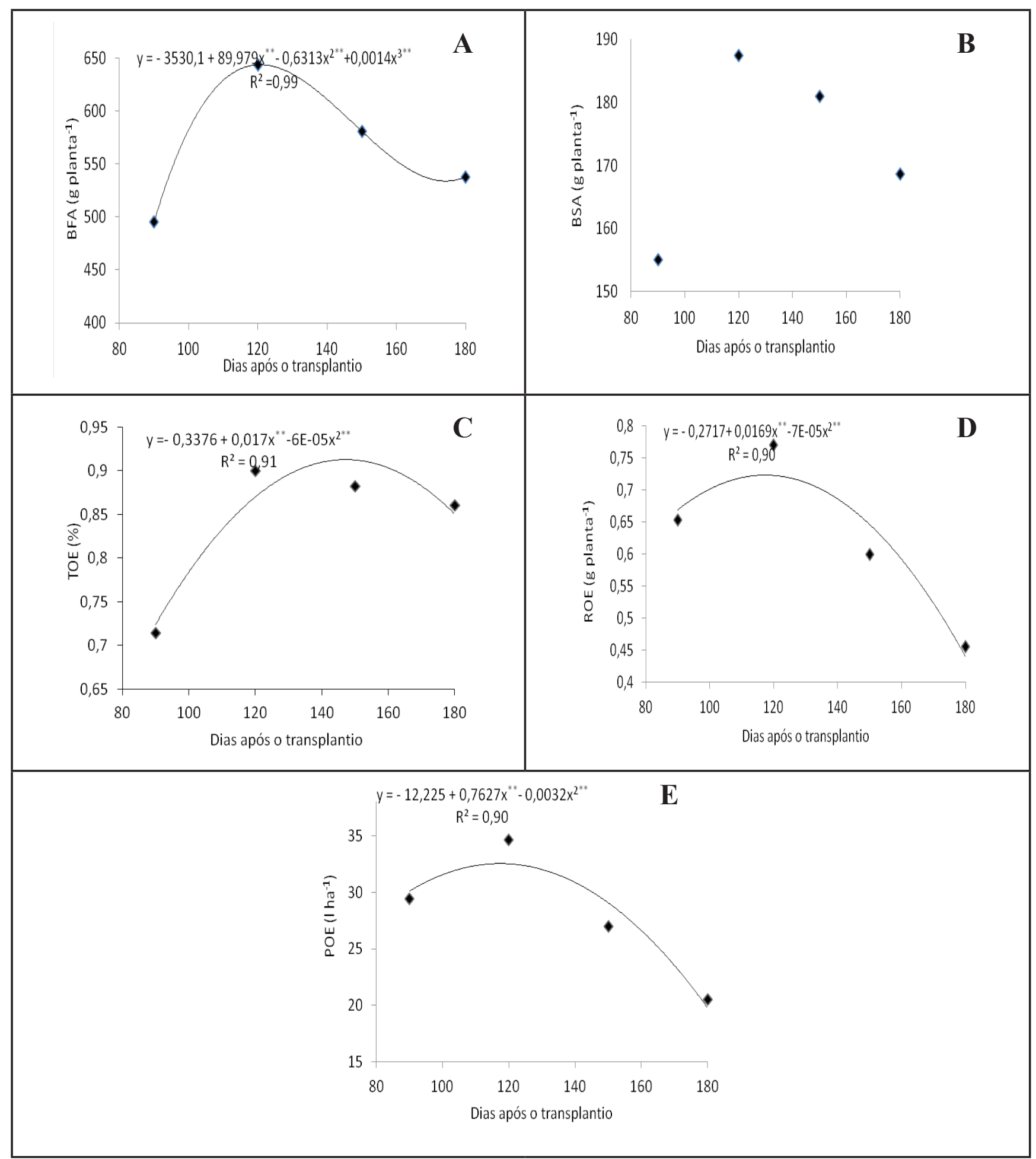

Figura 2. Biomassa fresca da parte aérea (BFA) (a); biomassa seca da parte aérea (BSA) (b); teor de óleo essencial (TOE) (c); rendimento de óleo essencial (ROE) (d) e produção de óleo essencial (POE) (e) de manjericão aos 90, 120, 150 e 180 dias após o transplantio (aboveground part fresh weight (BFA) (a); aboveground part dry weight of shoots (BSA) (b); content of essential oil (TOE) (c); essential oil yield (ROE) (d) and production of essential oil (POE) (e) of basil at 90, 120, 150 and 180 days after transplanting). Dois Vizinhos, UTFPR, 2013.

concentrado nos tricomas fosse volatizado pelas altas temperaturas e baixa umidade do ar.

A informação da época de maior produção de biomassa fresca e seca é muito importante para o produtor que, além de produzir óleo essencial, comercializa folhas para chás. Os resultados obtidos no estudo poderão contribuir para definição das colheitas, gerando suporte para produzir óleo essencial que atenda aos padrões exigidos pelo mercado e formulações de medicamentos fitoterápicos.

Lemberkovics et al. (1993), em tra- 
Tabela 4. Componentes do óleo essencial (\%) de manjericão em diferentes épocas de colheita (90, 120, 150 e 180 dias após transplantio) (components of the essential oil (\%) of basil in different harvest times (90, 120, 150 and 180 days after transplanting). Dois Vizinhos, UTFPR, 2013.

\begin{tabular}{lccrrr}
\hline \multirow{2}{*}{ Componentes } & \multirow{2}{*}{ I.K.* } & \multicolumn{4}{c}{ Dias após o transplantio } \\
\cline { 3 - 6 } & & $\mathbf{9 0}$ & $\mathbf{1 2 0}$ & $\mathbf{1 5 0}$ & $\mathbf{1 8 0}$ \\
\hline Mirceno & 1048,21 & $0,33 \mathrm{~d}$ & $0,65 \mathrm{a}$ & $0,36 \mathrm{c}$ & $0,54 \mathrm{~b}$ \\
1,8 Cineol & 1070,66 & $1,10 \mathrm{a}$ & $0,17 \mathrm{~d}$ & $0,94 \mathrm{~b}$ & $0,23 \mathrm{c}$ \\
Linalol & 1112,49 & $14,90 \mathrm{a}$ & $5,61 \mathrm{~d}$ & $11,31 \mathrm{~b}$ & $8,00 \mathrm{c}$ \\
Citronelal & 1149,59 & $0,56 \mathrm{a}$ & $0,39 \mathrm{~d}$ & $0,51 \mathrm{~b}$ & $0,46 \mathrm{c}$ \\
Terpinen-4ol & 1177,85 & $0,31 \mathrm{~d}$ & $0,37 \mathrm{c}$ & $0,46 \mathrm{~b}$ & $0,59 \mathrm{a}$ \\
Neral & 1231,93 & $26,38 \mathrm{~d}$ & $33,31 \mathrm{a}$ & $30,58 \mathrm{c}$ & $30,71 \mathrm{~b}$ \\
Geranial & 1261,84 & $36,22 \mathrm{~d}$ & $44,95 \mathrm{a}$ & $40,78 \mathrm{~b}$ & $39,22 \mathrm{c}$ \\
Eugenol & 1358,51 & $0,84 \mathrm{~b}$ & $0,64 \mathrm{c}$ & $0,63 \mathrm{~d}$ & $1,10 \mathrm{a}$ \\
$\beta$ B-Cariofileno & 1408,22 & $3,04 \mathrm{a}$ & $1,50 \mathrm{~d}$ & $2,05 \mathrm{~b}$ & $1,67 \mathrm{c}$ \\
Muuroleno & 1473,70 & $1,47 \mathrm{a}$ & $0,20 \mathrm{~d}$ & $0,83 \mathrm{~b}$ & $0,33 \mathrm{c}$ \\
Butirato de geranila & 1544,35 & $3,56 \mathrm{a}$ & $1,86 \mathrm{c}$ & $2,27 \mathrm{~b}$ & $1,78 \mathrm{~d}$ \\
Óxido de cariofileno & 1578,22 & $1,25 \mathrm{~d}$ & $1,99 \mathrm{~b}$ & $1,40 \mathrm{c}$ & $2,99 \mathrm{a}$ \\
\hline
\end{tabular}

*I.K. = índice de Kovats; **Médias seguidas das mesmas letras minúsculas nas linhas, em cada variável, não diferem estatisticamente pelo teste de Tukey, $\mathrm{p}<0,05$ (means followed by same lowercase letters in the lines in each variable are not statistically different by Tukey test, $\mathrm{p}<0,05$ ).

balhos com $O$. basilicum, observaram que no início do florescimento o óleo essencial se concentra em parte, nas folhas, e durante o pleno florescimento e estádios posteriores se concentra, principalmente, nas inflorescências. Observou-se que na floração ocorreu maior teor e rendimento de óleo essencial, e diminuição progressiva do teor e rendimento de óleo nas colheitas sucessivas (150 e 180 DAT) (Figura 2). Aos 180 DAT verificou-se que a planta estava no fim de seu ciclo produtivo, sem presença de flores, apenas sementes.

Tansi \& Nacar (2000), estudando Ocimum basilicum var. citriodorum observaram que a época de maior produção de óleo $(0,71 \%)$ foi no início da floração (90 DAT), com declínio de produtividade nas demais colheitas (120 e 150 DAT). De maneira semelhante, o teor de óleo essencial de Mentha x piperita citrata variou com a idade da planta, apresentando ajuste quadrático, com menores valores na primeira colheita (60 DAT) alcançando teor máximo (1\%) aos 120 dias, com decréscimo aos 210 dias, quando ocorreu a senescência da planta (Oliveira et al., 2012).

A análise cromatográfica dos óleos essenciais extraídos das plantas culti- vadas sob as diferentes malhas revelou grande variabilidade na composição química (Tabela 3). Os constituintes identificados foram geranial $(36,76$ a $41,68 \%)$, neral (28,13 a 31,57\%), linalol $(9,06$ a 11,02$)$, além de óxido de cariofileno, mirceno, 1,8 cineol, citronelal, terpinen-4-ol, eugenol, $\beta$-cariofileno, muuroleno, butirato de geranila em menores quantidades.

Independente do tratamento, o componente majoritário foi o citral (geranial + neral) que variou entre 64,89 e $73,25 \%$ (Tabela 3 ). Os maiores teores de geranial e neral foram obtidos nas malhas preta, aluminizada e pleno sol. $\mathrm{Na}$ malha vermelha se obteve os menores valores de geranial e neral. Os valores de citral estão próximos aos encontrados por Tansi \& Nacar (2000) estudando Ocimum basilicum var. citriodorum que obtiveram teores de citral entre 84,7 e 89,3\%. A importância comercial do óleo essencial de manjericão depende da percentagem desses dois componentes, bem como da baixa percentagem de outros componentes indesejáveis, como o nerol e geraniol, que são formas oxidativas do neral e geranial, e que afetam a qualidade do óleo essencial (Tabatabaie \& Nazari, 2007). Não foram encontrados esses componentes oxidativos no óleo essencial. Observou-se que o maior teor de citral no óleo essencial resultou em um distinto e forte aroma de limão, características condizentes àquelas descritas por Tansi \& Nacar (2000) para essa espécie.

A malha vermelha e pleno sol resultaram em maior teor de linalol em relação às demais malhas. Da mesma forma, Tansi \& Nacar (2000) também quantificaram o linalol como segundo componente em maior quantidade $(3,6$ a $5,8 \%)$ para $O$. basilicum var. citriodorum. O espectro de luz solar incidente que desfavoreceu a produção de citral na malha vermelha favoreceu a produção de linalol.

A composição química do óleo essencial pode ser bastante variável devido à diversidade genética, o habitat e os tratos culturais. Tansi \& Nacar (2000) afirmam que o citral é componente majoritário em $O$. basilicum var. citriodorum. O gene responsável pelo citral é dominante sobre os responsáveis pelos componentes geraniol e linalol em O. citriodorum (Sobti et al., 1978).

Entre as épocas de colheita realizadas, o componente químico majoritário foi o citral (geranial + neral), com valores de 62,20 a 78,26\% (Tabela 4). $\mathrm{Na}$ segunda colheita (120 DAT), quando a planta estava em plena maturidade, foram obtidos valores superiores $(78,26 \%)$ das demais colheitas e a primeira colheita (90 DAT) apresentou menor teor de citral $(62,20 \%)$. O maior teor de citral pode estar relacionado com a idade da planta aliada ao período de plena floração. O linalol se apresentou como o segundo componente de maior teor entre as colheitas, sendo que, na primeira colheita (90 DAT), alcançou maior teor (14,90\%), e, na segunda, o menor $(5,61 \%)$. Diferenças na composição química do óleo essencial, em relação à idade da planta, também foram encontradas por Oliveira et al. (2012) para Mentha piperita var. citrata, sendo essas, relacionadas às condições climáticas, à idade e ao estádio de desenvolvimento da planta.

Conclui-se que o cultivo sob malha aluminizada favoreceu o crescimento de manjericão. Aos 120 dias após o transplantio resultou em maior produção de 
biomassa fresca, óleo essencial $(0,77 \mathrm{~g} /$ planta) e teor de citral (78,26\%). Plantas de manjericão cultivadas sob pleno sol produziram maior biomassa fresca e seca, teor e rendimento de óleo essencial. O cultivo sob malhas não influenciou no aumento do teor e rendimento, mas sim na composição química do óleo essencial. O citral foi o constituinte majoritário do óleo essencial, sendo o maior teor presente no cultivo sob malhas preta, aluminizada e pleno sol.

\section{REFERÊNCIAS}

ALBUQUERQUE MB; HONÓRIO TL. 2008. Curva de crescimento e produção de biomassa em acessos de Ocimum basilicum var. citriodorum. Brasília: UnB. 22p. (Monografia graduação).

BHERING SB; SANTOS HG; BOGNOLA IA; CÚRCIO GR; MANZATTO CV; CARVALHO JÚNIOR W; CHAGAS CS; ÁGLIO MLD; SOUZA JS. 2008. Mapa de solos do Estado do Paraná: legenda atualizada. Rio de Janeiro: EMBRAPA/IAPAR. $74 p$.

BIASI LA; DESCHAMPS C. 2009. Plantas Aromáticas do cultivo aprodução deóleo essencial. Curitiba:Layer Studio Gráfico e Editora Ltda.160p.

BLANK AF; SOUZA EM; PAULA JWA; ALVES PB. 2010. Comportamento fenotípico e genotípico de populações de manjericão. Horticultura Brasileira 28: 305-310.

BRANT RS; PINTO JEBP; ROSA LF; ALBUQUERQUE CJB; FERRI PH; CORRÊA RM. 2009. Crescimento, teor e composicão do óleo essencial de melissa cultivada sob malhas fotoconversoras. Ciência Rural 39: 1401-1407.

COSTA AG; CHAGAS JH; PINTO JEBP; BERTOLUCCI SKV. 2012. Crescimento vegetativo e produção de óleo essencial de hortelã-pimenta cultivada sob malhas. Pesquisa Agropecuária Brasileira 47: 534540.

COSTA LCB; PINTO JEBP; CASTRO EM; ALVES E; ROSAL LF; BERTOLUCCI SKV; ALVES PB. 2010. Yield and composition of the essential oil of Ocimum selloi Benth. cultivated under colored netting. Journal of Essential Oil Research 22: 34-39.

FERNANDES PD. 2000. Análise de crescimento e desenvolvimento vegetal. Campina Grande: UFPB. 22p.

FIALLO VRF; MEDINA NNR; FERRADÁ CR. 1996. Acerca de Ia propagacion de Ocimum gratissimum L. Revista Cubana de Plantas Medica 1: 3-7.

GONÇALVES LA; BARBOSA LCA; AZEVEDO AA; CASALI VWD; NASCIMENTO EA. 2003. Produção e composição do óleo essencial de alfavaquinha (Ocimum selloi Benth.) em resposta a dois níveis de radiação solar. Revista Brasileira de Plantas Medicinais 6: 8-14.

INMET: Estação meteorológica A843 de Dois Vizinhos, PR. 2012. Disponível em http:// www.inmet.gov.br/sonabra/sonabra.html. Acessado em 30 de maio 2012.

KHOSLA MK; SOBTI SN. 1985. Karyo morphological studies in genus Ocimum II. Sanctum group. Cytologia 50: 253-63.

LARCHER W. 2004. Ecofisiologia vegetal. São Carlos: RiMa Artes e Textos, 531p.

LEITE CA; ITO RM; LEE GTS; GANELEVIN R; FAGNANI MA. 2008. Light spectrum management using colored nets to control the growth and blooming of Phalaenopsis. Acta Horticulturae 770: 177-184.

LEMBERKOVICS EH; NGUYEN K; TARR IJ; PETRI G; VITANYI GY. 1993. Formation of biologically active substances of $O$. basilicum during the vegetation period. Acta Horticulturae 344: 334-346.

LORENZI H; MATOS FJA. 2008. Plantas medicinais no Brasil: nativas e exóticas. Nova Odessa: Plantarum. 544p.

LOUGHRIN JH; KASPERBAUER MJL. 2001. Light reflected from colored mulches affects aroma and phenolic content of sweet basil (Ocimum basilicum L.) leaves. Journal of Agricultural and Food Chemistry 49: 13311335.

MARTINS JR; ALVARENGAAA; CASTRO EM; PINTO JEBP; SILVA APO. 2008. Avaliação do crescimento e do teor de óleo essencial em plantas de Ocimum gratissimum L. cultivadas sob malhas coloridas. Revista Brasileira de PIantas Medicinais 10: 102-107.

MORAIS LAS. 2009. Influência dos fatores abióticos na composição química dos óleos essenciais. Horticultura Brasileira 27: 50-63.

OLIVEIRA ARMF; JEZLER CN; OLIVEIRA RA; COSTA LCB. 2012. Influência da idade da planta na produção de óleo essencial de alevante. Revista Ceres 59: 241-245.

OREN-SHAMIR M; GUSSAKOVSKY EE; SPIEGEL E; NISSIM-LEVI A; RATNER
K; OVADIA R; GILLER YE; SHAHAK Y. 2001. Colored shade nets can improve the yield and quality of green decorative branches of Pittosphorum variegatum. Journal of Horticultural Science and Biotechnology 76: 353-361.

SAS INSTITUTE. 1999. SAS: user's guide statistics: version 8.0 edition. Cary. 956 p.

SHAHAK Y; GUSSAKOVSKY EE; GAL E; GAELEVIN R. 2004. Colornets: crop protection and light-quality manipulation in one technology. Acta Horticulturae 659: 143-161.

SIFOLA MI; BARBIERI G. 2006. Growth, yield and essential oil content of three cultivars of basil grown under different levels of nitrogen in the field. Scientia Horticulturae 108: 408-413.

SOBTI SN; PUSHPANGADAN RK; THAPA SG; AGGARWAL VN; VASHIST CK. 1978. Chemical and genetic investigations in essential oils of some Ocimum species, their hybrids and synthesized allopolyploids. Loydia 41: 50-55.

SOUZA GS; CASTRO EM; SOARES AM; SANTOS AR; ALVES E. 2011. Teores de pigmentos fotossintéticos, taxa de fotossíntese e estrutura de cloroplastos de plantas jovens de Mikania laevigata Schultz Bip. ex Baker cultivadas sob malhas coloridas. Semina 32 : 1843-1854.

TABATABAIE SJ; NAZARI J. 2007. Influence of nutrient concentrations and $\mathrm{NaCl}$ salinity on the growth, photosynthesis and essential oil content of peppermint and lemon verbena. Turkish Journal of Agriculture and Forestry 31: 245-253.

TANSI S; NACAR S. 2000. First cultivation trials of lemon basil (Ocimum basilicum var. citriodorum) in Turkey. Pakistan Journal of Biological Sciences 3: 395-397.

TAVEIRA FSN; LIMA WN; ANDRADE EHA; MAIA JGS. 2003. Seasonal essential oil variation of Aniba canelilla. Biochemical Systematics and Ecology 31: 69-75.

TSORMPATSIDIS E; HENBEST RGC; DAVIS FJ; BATTEYA NH; HADLEYA P; WAGSTAFFE A. 2008. UV irradiance as a major influence on growth, development and secondary products of commercial importance in Lollo Rosso lettuce 'Revolution' grown under polyethylene films. Environmental and Experimental Botany 63: 232-239.

VIEIRA RF; GOLDSBROUGH P; SIMON JE. 2003. Genetic diversity of basil (Ocimum spp.) based on RAPD markers. Journal of the American Society for Horticultural Science 128: 94-99. 